\title{
The frustration vigor effect (FVE) as a function of number of rewarded barpress trials'
}

MELVIN H. MARX AND JO W. TOMBAUGH UNIVERSITY OF MISSOURI, COLUMBIA

An increment in response vigor was observed in extinction performance as a function of the number of massed training responses, with total number of training rewards controlled. This empirical demonstration of a frustration vigor effect on the learned response is seen as offering a methodological altemative to the double-runway for the analysis of frustration effects.

The purpose of this experiment was to determine the effects on resistance to extinction of the number of rewarded bar-press (BP) training trials, with the total number of training rewards controlled.

\section{Method}

Sixteen young, naive, female albino rats were trained and tested in a single session. The apparatus was the controlled operant conditioning box (Marx et al, 1965), utilizing retractable bars for discrete trial programming. All 23-hr food-deprived Ss received 48 training trials and 24 test (extinction) trials, with no time break from training to extinction.

The differentiating variable was the point at which magazine training changed to BP training. Thus Group 12/36 received 12 magazine trials with the reward directly presented, followed immediately by 36 rewarded BP trials; Group 24/24 received 24 of each kind of training trial; Group 36/12 received 36 magazine and 12 rewarded BP training trials; and Group $48 / 0$ received 48 magazine trials and $0 \mathrm{BP}$ trials. The 24 extinction trials involved presentation of the bar and offering of an empty magazine if the bar was pressed.

The intertrial interval for magazine trials was 60 sec. All BP trials allowed $60 \mathrm{sec}$ both for bar presentation and between bar retraction (whether produced by the S's press or automatically at the end of the trial) and the next bar presentation. Each of the 48 training trials provided $\mathrm{S}$ with $.05 \mathrm{ml}$ of $16 \%$ sucrose solution. A BP trial in training was defined by the actual making of the press and the consequent operation of the magazine, rather than by the offering of the bar. This procedure was necessary in order to insure that all of the training rewards, preloaded in the 72-hole plate magazine used, were offered to $\mathrm{S}$ before the onset of extinction.

\section{Resulis}

Figure 1 shows mean latencies of BPs made during training and test. The major point of interest within the present context is the decrement in latency (increase in speed) apparently induced by the onset of continuous nonreward in the three groups which had bar-press experience in training. The differences between means for the last six trials prior to and the first six trials following nonreward were analyzed by $t$ tests. The effect was statistically reliable only for Groups 12/36 and 24/24-ps of .01 and .05, respectively (and $p>.10$ for Group 36/12). The groups for which the difference was reliable had the greater number of BPs and had approached asymptotic barpress latency more closely than Group 36/12. The differences between means for the last two blocks of reinforced trials of Groups 12/36 and 24/24 were also analyzed and were not reliable (ps $>.20$ ), suggesting that the apparent FVE was not merely an artifact of failure to approach a training asymptote.

Curves for individual Ss in Group 12/36, shown in Fig. 2, provide further evidence that the increased response vigor was not simply an extension of acquisition performance. Further, the persistence of the reduced latency in each case over all of the nonrewarded BP trial blocks is impressive evidence of the strength of the apparent FVE. A similar but less pronounced effect was observed in all of the individual $\mathrm{Ss}$ in Group 24/24.

As can be seen in Fig. 1, resistance to extinction was an increasing function of the number of BP responses made in training (ps of .01 and .05 for the first-block and fourth-block group differences, respectively). Further, the lack of any difference be-

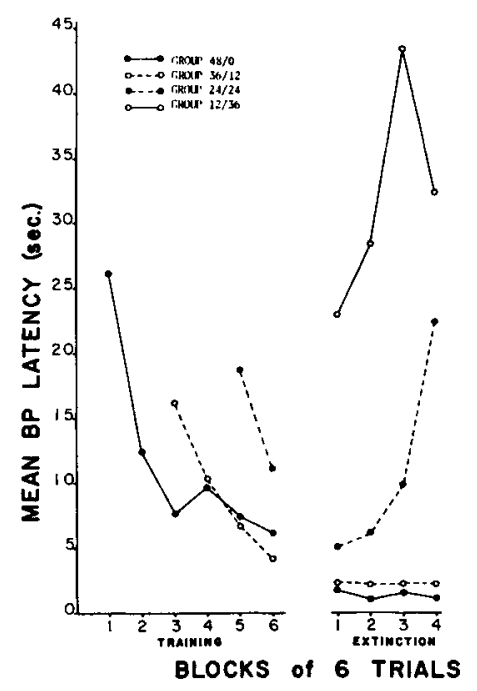

Fig. 1. Mean latencies of barpresses made in training and extinction. 


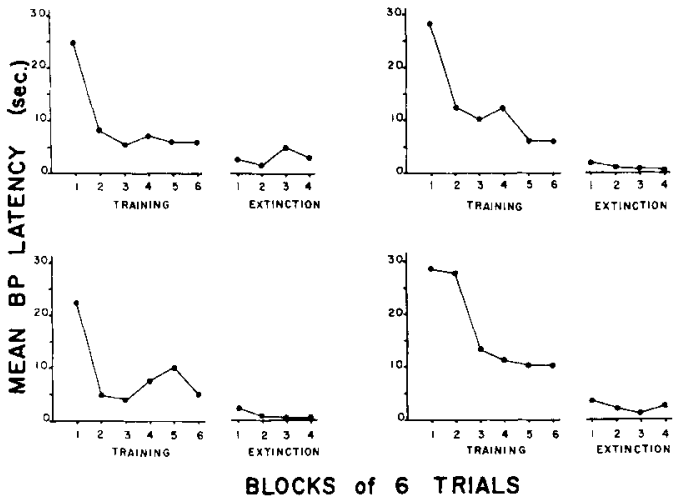

Fig. 2. Mean latencies of barpresses made in training and extinction for individual Ss in Group $12 / 36$.

tween Group 24/24 and Group 12/36 supports the assumption of Theios \& Brelsford (1964), based on runway data, that there is an early asymptote in instrumental response strength in extinction as a function of number of training responses.

\section{Discussion}

The demonstration of a very quick FVE, clearly within the first six test trials, serves to distinguish the present effect from the response facilitation of recurrent blocks of nonrewarded trials which has been occasionally noted (e.g., Jensen \& Cotton, 1960). The discrete-trial character of the present data also distinguishes them from free-operant data, in which a temporary facilitation has been noted and attributed to emotion developing after the initiation of extinction (e.g., Skinner, 1938).

It is possible that the highly massed training conditions used in this experiment are necessary for the appearance of a FVE on the relevant response, since they serve to depress the asymptote approached in training and thereby allow more opportunity for an increment in response vigor in extinction. By this reasoning, experimental conditions which maximize performance in training may also be viewed as tending to mask the FVE in extinction (e.g., the 24-hr intertrial interval between training and test, presumably permitting the dissipation of emotional effects such as those produced by frustration).
The demonstration of a relevant-response FVE in the present data is consistent with the fundamental assumption of Amsel's (1958) frustration theory. Whereas in the familiar double-runway apparatus the invigorating effect is measured on the immediately succeeding response, in the discrete-trial operant situation it is measured on the same response with a minimum time interval from training to extinction. The present experimental situation thus affords an alternative method of measuring the FVE.

These data, suggesting that there is in fact an FVE that serves to energize the learned response, do not bear directly on the question as to whether the FVE also energizes other, potentially interfering responses. It is of course possible in the case of Group 36/12 that the FVE directly affected irrelevant, and interfering, responses, so as to produce the more rapid extinction characteristic of lesser amounts of rewarded BP training. However, as has been pointed out (Marx, 1963), there is a great need for direct empirical evidence as well as clearer specification of the mechanisms by which interfering or competing responses operate in extinction.

\section{References}

Amsel, $\boldsymbol{A}$. The role of frustrative nonreward in noncontinuous reward situations. Psychol. Bull., 1958, 55, 102-119.

Birch, D. A motivational interpretation of extinction. In $M$. R. Jones (Ed.), Nebraska symposium on motivation. 1961. Lincoln: University of Nebraska Press, 1961.

Jensen, G. D., \& Cotton, J. W. Successive acquisition and extinctions as related to percentage of reinforcement. J. exp. Psychol., 1960, 60, 41-49.

Marx, M. H. The need for more specific formulations of the "com" peting response" interpretation of extinction. Psychol. Rep., $1963,12,729-730$.

Marx, M. H., Tombaugh, T. N., Hatch, R. S., \& Tombaugh, Jo W. Controlled operant conditioning boxes with discrete-trial programming for multiple experimental use. Percept. mot. Skills, $1965,21,247-254$.

Skinner, B. F. The behavior of organisms: An experimental analysis. New York: Appleton-Century-Crofts, 1938.

Theios, J., \& Brelsford, J. Overlearning-extinction effect as an incentive phenomenon. $J$. exp. Psychol., 1964, 67, 463-467.

\section{Note}

1. This research was supported in part by USPHS Research Grant HD-00895 from the National Institute of Child Health and Human Development and by USPHS Research Career Award 1-K6-MH-22,023 from the National Institute of Mental Health, to the first author. 